NASA Technical Memorandum 100873

AIAA-88-2055

\title{
Porous Wind Tunnel Corrections for Counterrotation Propeller Testing
}

\begin{tabular}{l} 
(NASA-TH-100873) POROOS NIND TUNNEL \\
CORBECTIONS FOR COUNTERROTATION PROPELLER \\
TESTING (NASA) $18 \mathrm{p}$ \\
\hline
\end{tabular}

George L. Stefko and Robert J. Jeracki

Lewis Research Center

Cleveland, Ohio

Prepared for the

15th Aerodynamic Testing Conference

sponsored by the American Institute of Aeronautics and Astronautics

San Diego, California, May 18-20, 1988 
POROUS WIND TUNNEL CORRECTIONS FOR COUNTERROTATION PROPELLER TESTING

\author{
George L. Stefko and Robert J. Jeracki \\ National Aeronautics and Space Administration \\ Lewis Research Center \\ Cleveland, Ohio 44135
}

\title{
SUMMARY
}

Wind tunnel interference corrections have a direct impact on measured propeller efficlency. A systematic series of wind tunnel tests were done in the porous wall NASA Lewis 8- by 6-Foot Wind Tunnel to determine the wind tunnel interference corrections to the NASA Lewis counterrotation propeller test data. The test results were compared with calculations from a potential flow code to determine the interference corrections. At a Mach number of 0.8 , the interference corrections resulted in a -0.008 Mach number correction which reduced the counterrotation propeller net efficiency data by 0.46 percent at the reduced Mach number. Additional wind tunnel tests were done to measure the effect of propeller thrust on wind tunnel wall interference. No wall interference corrections due to propeller thrust were found necessary for the high speed counterrotation propeller data obtained in the porous wall NASA Lewis 8- by 6-Foot Wind Tunnel.

\section{INTRODUCTION}

The counterrotation propeller test rig is shown in the NASA Lewis 8- by 6-Foot Wind Tunnel in figure 1. In this figure, the slotted holes in the tunnel walls which provide a 5.8 percent porosity in the $14 \mathrm{ft}$ test section, can be seen. In the past, the porosity of the test section had been assumed to cancel out the need for any interference corrections in the single and counterrotation propeller test data. This assumption appeared valid due to good correlation between NASA and Hamilton Standard's single rotation propeller test results obtained in different facilities on the same propeller models.

This good correlation between NASA and Hamilton Standard was especially encouraging because of the large differences between wind tunnels and propeller test rigs. The United Technologies Research Center (UTRC) Wind Tunnel was a solid wall wind tunnel versus the porous wall NASA Lewis Wind Tunnel. Further, the electric drive test rig and the thrust and torque measuring system used at UTRC were significantly different in design from the turbine drive propeller test rig used at NASA. Also, a special calibration procedure was followed in the UTRC solld wall tunnel to account for wall interference effects. The good correlation in data obtalned in these two facilities suggested that any interference corrections for the NASA 8- by 6-Foot Wind Tunnel were small, around 1 percent or less. With the advent of counterrotation propeller testing, however, the larger blockage of the counterrotation test rig could represent a significant unknown interference correction to the propeller data. Therefore, the decision was made to determine the interference corrections.

This paper reports on the wind tunnel tests that were made to experimentally determine the magnitude of the interference corrections required for counterrotation propeller testing in the NASA Lewis 8-by 6-Foot Wind Tunnel. 
Also presented are the results of tests conducted to measure the effect of propeller thrust on wind tunnel wall interference. The tests reported on were done for Mach numbers from 0.6 to 0.9 which represent the Mach number region where the counterrotation propeller testing was done.

\section{WIND TUNNEL AND PROPELLER TEST RIG}

The NASA Lewis 8- by 6-Foot Wind Tunnel was designed for transonic testing. The wind tunnel can operate at Mach numbers from 0.4 to 2.0 . The $14 \mathrm{ft}$ test section used in this test incorporated a perforated test section with 5.8 percent porosity to minimize model-wall interactions. Additional details on this facility can be found in reference 1 .

The counterrotation test rig ( $f i g .1)$ has a propeller diameter of $24.64 \mathrm{in}$. On the front propeller and 23.95 on the rear propeller. The blockage characteristics of the test rig are listed in table I.

\section{INSTRUMENTATION}

Two pitot-static pressure rakes for measuring the flowfield around the counterrotation propeller test rig are shown in figure 2 . The probes on these rakes were spaced 6 in. apart and the rakes were mounted on the top, bottom, left, and right of the counterrotating propeller test rig in the propeller plane. A long pitot-static calibration probe was used to calibrate these rakes in the tunnel. These rakes were used with no blades installed on the counterrotation test rig.

For measuring the effect of propeller thrust, a $20 \mathrm{ft}$ long static tube was used on the floor and ceiling of the tunnel. Figure 3 shows the static tube mounted on the ceiling of the tunnel. The tube had a total of 81 active static pressure taps located at 27 axial stations. Three pressure taps at each axlal location were situated with one on each side and one on the top of the tube. The static tube measured the static pressure 10 in. from the tunnel floor and celling.

The wind tunnel Mach number was determined from eight total pressures in the bellmouth of the tunnel and four static pressures in the balance chamber which surround the tunnel porous walls. These pressures were used with a tunnel calibration program which used existing tunnel calibration data to calculate the wind tunnel Mach number, MMeasured. This MMeasured Mach number was used for counterrotation propeller data presented to the present time. The accuracy of the pressure measurements used in the test was $\pm 0.03 \mathrm{psia}$.

\section{ANALYTICAL WORK}

The potential flow computer program that was used for comparison to experimental data calculates the compressible potential flow about axisymmetric bodies of arbitrary shape. This analysis is described in detail in reference 2. It was used to calculate the velocity ratios that would exist around the counterrotation propeller test rig without blades in free air. The body shape downstream of the propeller was an afterbody and a simulated exhaust plume which decreased to a constant diameter section. The diameter then expanded to 
become the turbine housing to which the support strut attached. For the isolated analytical model, the turbine housing and support strut were replaced by a constant diameter cylinder continuing downstream representing an exhaust jet.

\section{TEST RESULTS FOR INTERFERENCE CORRECTIONS}

Comparisons of the analytical and experimental velocity ratios are presented in figures 4 to 7 for the Mach numbers of $0.6,0.7,0.8$ and 0.85 , respectively. The local to free-stream velocity ratio at the propeller plane (tunnel station 150 ) is plotted versus radial distance from model centerline. The experimental data is plotted for the rake located at four different circumferential positions above, below, to the left, and to the right of the counterrotation propeller test rig. The data, especially near the propeller, generally clusters together indicating an axisymmetric flowfield at the propeller plane. The rakes accurately measured the varlations in the local flowfield surrounding the propeller rig caused by all sources including the strut, the rig, and the tunnel itself.

The analytical velocity ratlos from the potential flow computer program shown on figures 4 to 7 represent the flowfield that would exist around the propeller nacelle in free air ( $1 . e .$. no tunnel walls). The difference between the analytical curve and the experimental data shown in these figures are small and represent the needed interference correction. To obtain this correction, the free-stream velocity in the denominator of the experimental velocity ratio must be adjusted since the local velocity in the numerator is directly measured. The free-stream velocity is reduced until the ratio generally agrees with the analytical value.

The corresponding Mach number interference corrections for the counterrotating propeller test rig operating in the NASA Lewis 8- by 6-Foot Wind Tunnel are shown in figure 8 . In this figure, a delta Mach number correction is plotted versus measured tunnel Mach number. The delta Mach number correction is negative and can be applied to obtain a corrected Mach number using the equation:

\section{MCORRECTED $=$ MMEASURED $+\Delta M$}

At a tunnel measured free-stream Mach number of 0.8 , the delta Mach number correction is -0.008 which reduces the Mach number in the propeller plane to 0.792 . The correction is -0.011 at Mach 0.85 and -0.006 at Mach 0.7 .

The net propeller efficiency is directly related to free-stream velocity as shown in the equation below:

$$
n_{\text {NET }}=\frac{\text { FREE-STREAM VELOCITY * NET THRUST }}{\text { SHAFT POWER }}
$$


In dimensionless form, the efficlency equation becomes:

$$
n_{N E T}=\frac{J * c_{T}}{C_{P}}
$$

where

$$
J=\frac{\text { FREE-STREAM VELOCITY }}{\text { PROPELLER DIAMETER * ROTATIONAL SPEED }}
$$

Since the interference correction reduces the free-stream velocity, the net efficiency data will be reduced. The effect of this correction on counterrotation net efficiency data is presented in figures 9 to 11 for the F7/A7 blades at Mach numbers of 0.67 to 0.85 . The original data is represented by the circles and the squares represent the corrected data. For example, at Mach 0.8 and the advance ratio of 3.12 ( $\mathrm{fig} .11$ ), the original efficiency was 77.7 percent. The net efficlency, evaluated at the same advance ratio and power, was determined to be reduced -0.46 percent. Thus, the corrected new efficiency is 77.24 percent. Table II below lists the reduction in NASA Lewis counterrotation propeller net efficiency data at five different operating conditions.

\section{EFFECT OF PROPELLER THRUST ON WALL INTERFERENCE}

The counterrotating propeller test rig and the $20 \mathrm{ft}$ long static tube are shown in the NASA Lewis 8- by 6-Foot Wind Tunnel (fig. 12). These test tools were used to measure the effect of propeller thrust on tunnel wall interference. The static tube measured the static pressure $10 \mathrm{in}$. from the tunnel celling and floor at 27 axial stations.

The test objective was to determine any additional wall interference corrections to apply to the propeller data that would be caused by the thrust generated by the propellers. The static tube was used to measure the change in pressures caused by the propeller thrust. The Mach number was then calculated from these pressures and the tunnel total pressure. In figure 13, the Mach number at the propeller plane near the floor is shown versus the thrust generated by the propellers for a free-stream Mach number of 0.8 . This figure shows no significant change in Mach number as the propeller thrust is varied from the windmill value of $-80 \mathrm{lb}$ to the maximum thrust value of $573 \mathrm{lb}$.

The theoretical Glauert curve for solid wall wind tunnels (ref. 3) and additional data for the porous wall 8 - by 6-Foot Wind Tunnel are presented in figure 14. The propeller plane velocity to reference velocity ratio is plotted versus the thrust coefficient at Mach numbers from 0.67 to 0.9 with the static tube located on both the floor and ceiling. In a porous wall wind tunnel, no equivalent velocity exists to the Glauert reference velocity far upstream in the solid wall tunnel. Consequently, the velocity near zero thrust was used as the reference. Also, the experimental thrust coefficient has a compressibility correction (ref. 4) applied in order to compare directly with the incompressible Glauert equation. The data scatters to the limits of the experimental accuracy over the wide range of Mach numbers but generally shows no change in propeller plane velocity ratio with increasing thrust coefficient. The solid wall Glauert curve indicates that at a thrust coefficient of 0.4 , 
the propeller plane velocity ratio in a solid wall wind tunnel would be reduced about 1.2 percent. Measurements made in the solid wall NASA Lewis 10- by 10-Foot Wind Tunnel for propeller tests in that tunnel agreed with the Glauert curve and the corrections were made to the propeller test data obtained in that tunnel. That data analysis is reported in reference 5.

The effect of propeller thrust on Mach numbers over the length of the tunnel test section near the ceiling and the floor are shown in figures 15 and 16 , respectively. The square symbols represent a windmill thrust around $-851 \mathrm{~b}$ while the triangle symbols represent the maximum thrust near $575 \mathrm{lb}$. No significant difference in Mach numbers between the minimum and maximum thrust are seen along the length of the test section. This lack of change in the Mach numbers is especially true around the important propeller plane tunnel station of 150 .

Thus the measurements for the effect of thrust on wall interferences show that no corrections are needed for the counterrotation propeller test rig at Mach numbers from 0.67 to 0.9 in the porous wall NASA Lewis 8- by 6-Foot Wind Tunnel.

The effect of the counterrotation test rig and strut can also be seen in figure 16 at a Mach number of 0.8 . The leading edge of the unswept strut is located at tunnel station 194. The suppression of the Mach number in front of the strut can be seen in the figure with the lowest Mach number of 0.768 occurring at tunnel station 182. If the same calibration procedure were done in this lower Mach number flowfield, the corrected free-stream Mach number would have been reduced similarly and the net efficiency at the same power would have required a correction of about -2 percent. However, the figure indicates that at tunnel station 161, the near wall Mach number has recovered to where it started at Mach 0.804 well before it reaches the aft propeller plane at tunnel station 150. It can also be seen at tunnel station 217 , the flow reaches its maximum speed of Mach 0.86 at the axial location of the maximum thickness of the strut.

Another approach to see if the strut on the bottom of the rig has suppressed the Mach numbers into the propeller flowfield is to look at the Mach number distributions on the surface of the counterrotation propeller test rig. In figure 17, the Mach numbers at different angular positions on the surface of the counterrotating propeller test $r i g$ are shown at a free-stream Mach number of 0.8 with the propellers at windmill conditions. If the Mach numbers on the afterbody behind the propellers at the $180^{\circ}$ angular location were lower than at $0^{\circ}$, then there would be an indication the strut suppressed the Mach numbers. No evidence of significant differences in Mach numbers between the top and bottom of the afterbody is indicated in this figure. Thus, figures 15 to 17 indicate that the strut did not significantly suppress the Mach numbers in the propeller flowfield. Further, the calibration procedure uses data obtained from rakes which accurately measured any effects of the strut and the turbine housing on the propeller flowfield and accounts for them through the interference corrections.

\section{CONCLUSIONS}

The interference corrections for counterrotation propeller testing in the porous wall NASA Lewis 8- by 6-Foot Wind Tunnel have been determined for Mach 
numbers between 0.6 and 0.9 . For example, at a Mach number of 0.8 , the interference correction from figure 8 is a -0.008 reduction in the Mach number.

This Mach number correction, at the same power coefficient and advance ratio, will reduce the counterrotation net efficiency by 0.46 percent. The effect on efficiency for other Mach numbers can be found in table II.

The effect of propeller thrust on wall interference was measured. No wall interference correction for propeller thrust is necessary for the high speed counterrotation propeller data in the porous wall 8- by 6-Foot Wind Tunnel.

No significant reduction in propeller plane Mach numbers due to the strut was measured near the wall with the $20 \mathrm{ft}$ long static tube. Also, there was no significant circumferential variation of the Mach number on the counterrotation propeller test rig which indicates that the strut did not measurably suppress the flow at the propeller plane.

\section{REFERENCES}

1. Swallow, R.J., and Aiello, R.A., "NASA Lewis 8- by 6-Foot Supersonic Wind Tunnel," NASA TM X-71542, 1974.

2. Hess, J.L., and Smith, A.M.O., "Calculation of Potential Flow About Arbitrary Bodies," Progress in Aeronautical Sciences, Vol. 8, D. Kuchemann, ed., Pergamon Press, New York, 1967, pp. 1-138.

3. Glauert, H., "Wind Tunnel Interference on Wings, Bodies, and Airscrews," ARC R\&M No. 1566, British Aeronautical Research Center, 1933.

4. Young, A. D., "Note on the Application of the Linear Perturbation Theory to Determine the Effect of Compressibility on the Wind Tunnel Constraint on a Propeller," ARC R\&M No. 2113, British Aeronautical Research Center, 1944.

5. Stefko, G. L., and Jeracki, R.J., "Wind-Tunnel Results of Advanced High-Speed Propellers at Takeoff, $\mathrm{Cl}$ imb, and Landing Mach Numbers," NASA TM-87030, 1986. 
TABLE I. -

\begin{tabular}{|c|c|c|c|}
\hline Description & $\begin{array}{c}\text { Axial } \\
\text { location, } \\
\text { tunnel } \\
\text { station }\end{array}$ & $\begin{array}{c}\text { Diameter, } \\
\text { inches }\end{array}$ & $\begin{array}{c}\text { Blockage, } \\
\text { percent }\end{array}$ \\
\hline $\begin{array}{c}\text { Maximum forebody } \\
\text { diameter }\end{array}$ & 138 & 11.94 & 1.62 \\
\hline $\begin{array}{c}\text { Forward propeller } \\
\text { plane nacelle }\end{array}$ & 147 & 10.58 & 1.27 \\
\hline $\begin{array}{c}\text { Forward propeller } \\
\text { blades and nacelle }\end{array}$ & 147 & 24.64 & 1.38 \\
\hline $\begin{array}{c}\text { Maximum blockage at } \\
\text { rear support strut }\end{array}$ & 217 & --03 \\
\hline
\end{tabular}

TABLE II. -

\begin{tabular}{|c|c|c|c|}
\hline $\begin{array}{c}\text { Measured Mach } \\
\text { number }\end{array}$ & $\begin{array}{c}\text { Corrected Mach } \\
\text { number }\end{array}$ & $\begin{array}{c}\text { Advance } \\
\text { ratio }\end{array}$ & $\begin{array}{c}\text { Net efficiency } \\
\text { change, } \\
\text { percent }\end{array}$ \\
\hline 0.670 & 0.665 & 2.61 & -0.30 \\
.720 & .714 & 2.81 & -.31 \\
.760 & .753 & 2.97 & -.39 \\
.800 & .792 & 3.12 & -.46 \\
.850 & .839 & 3.32 & -.61 \\
\hline
\end{tabular}




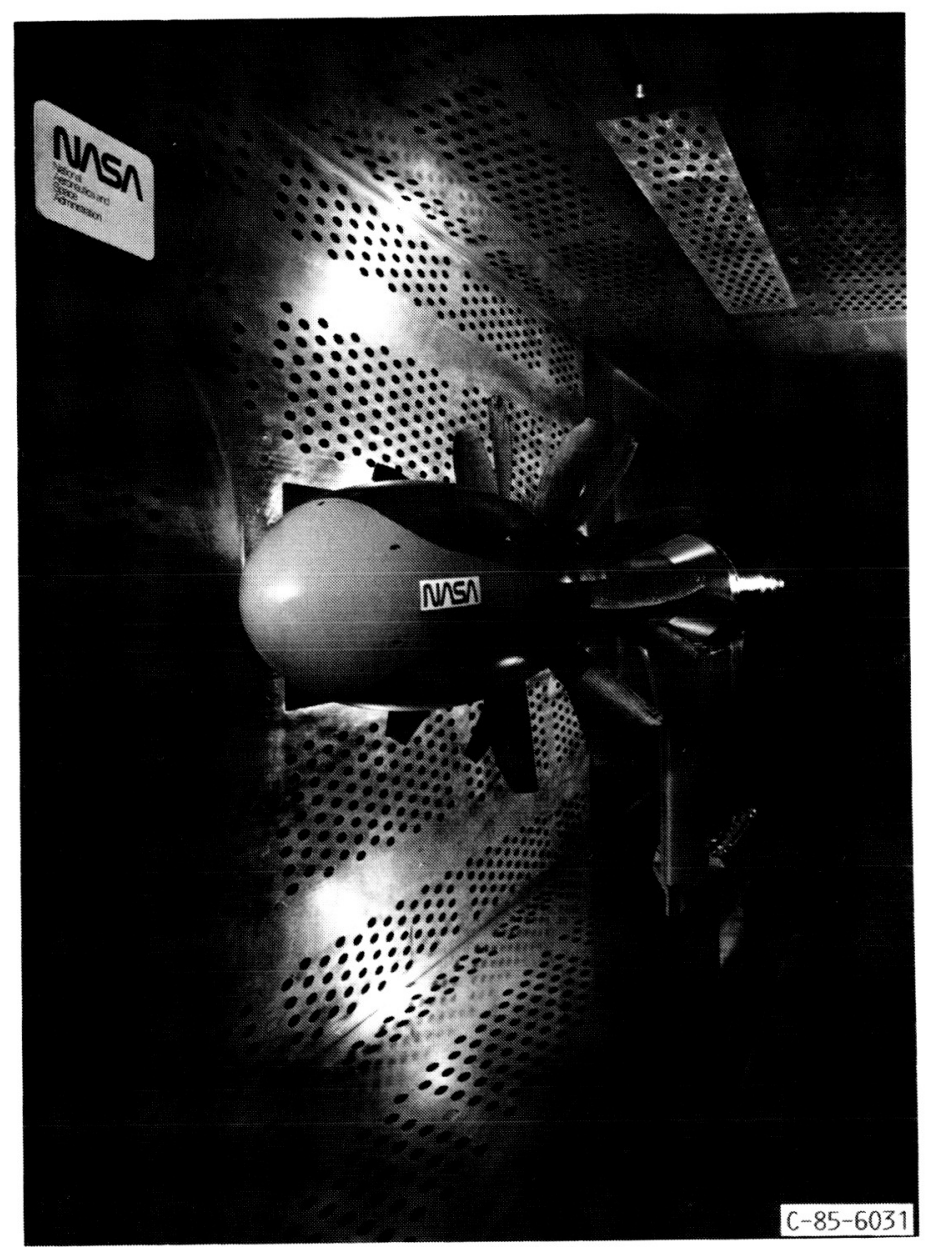

FIGURE 1. - COUNTERROTATING PROPELLER TEST RIG IN THE POROUS WALL NASA LEWIS 8X6 FOOT WIND TUNNEL. 


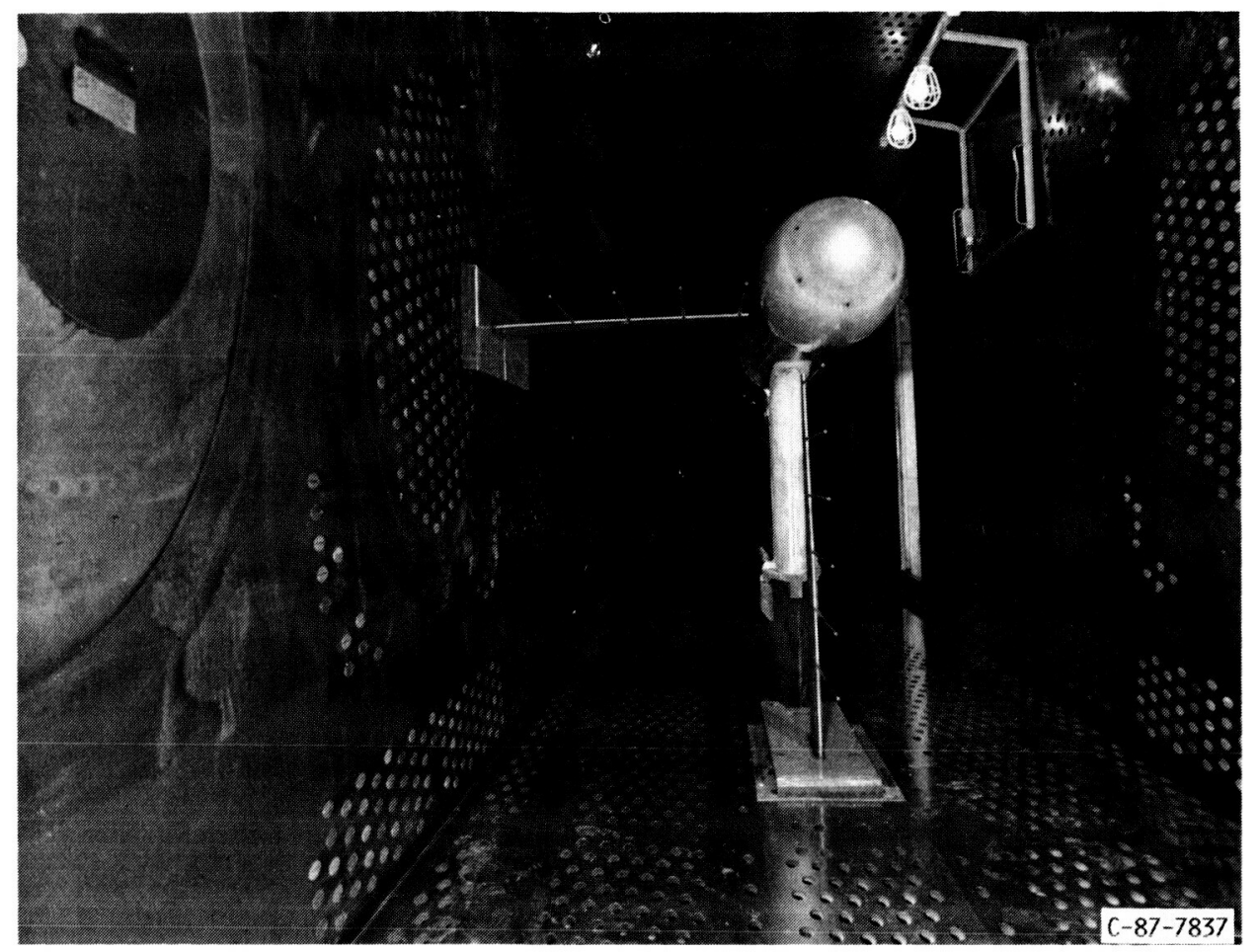

FIGURE 2. - TWO RAKES FOR MEASURING THE FLOWFIELD PRESSURES AROUND THE COUNTERROTATING ORIGINAT PAGE IS PROPELLER TEST RIG.

OF POOR QUALITY

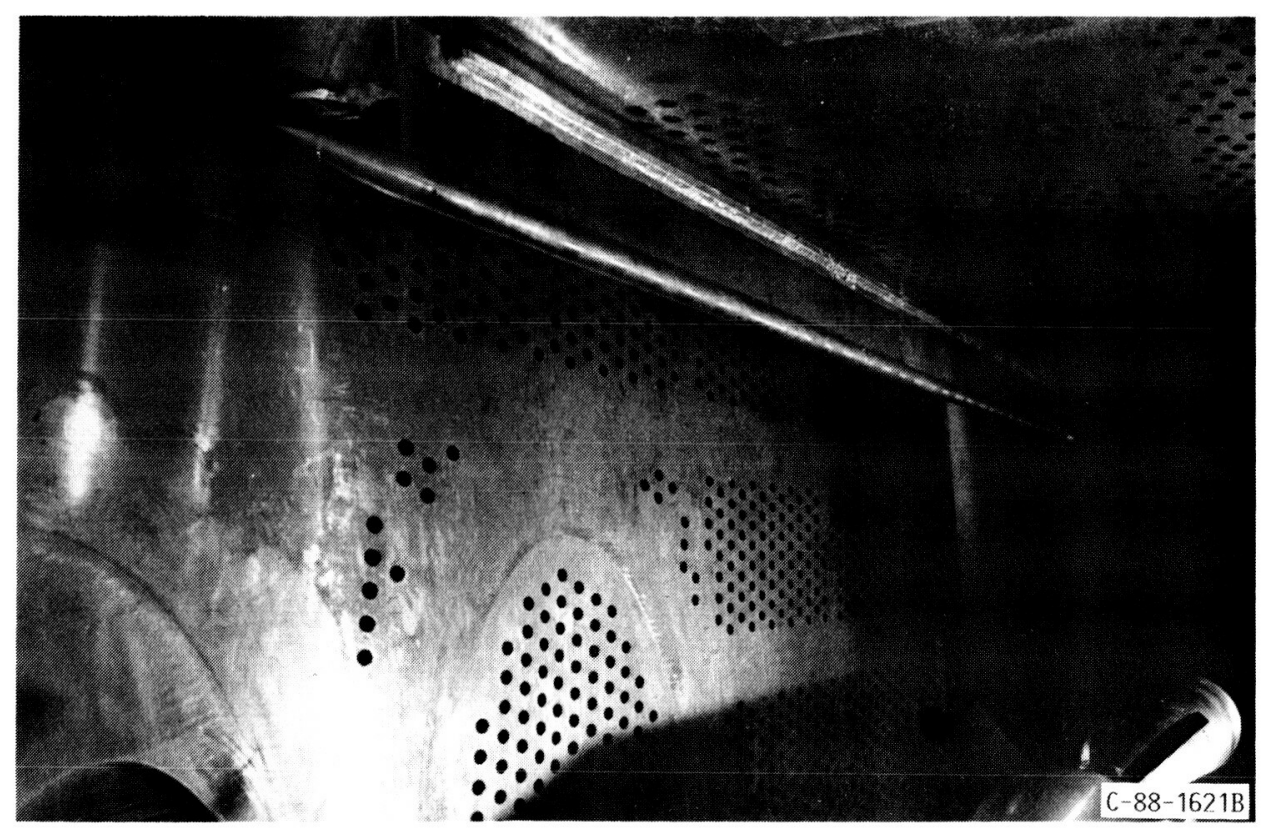

FIGURE 3. - TWENTY-FOOT STATIC TUBE USED FOR MEASURING PRESSURES OVER THE POROUS LENGTH OF THE $8 \times 6$ FOOT WIND TUNNEL TEST SECTION. 


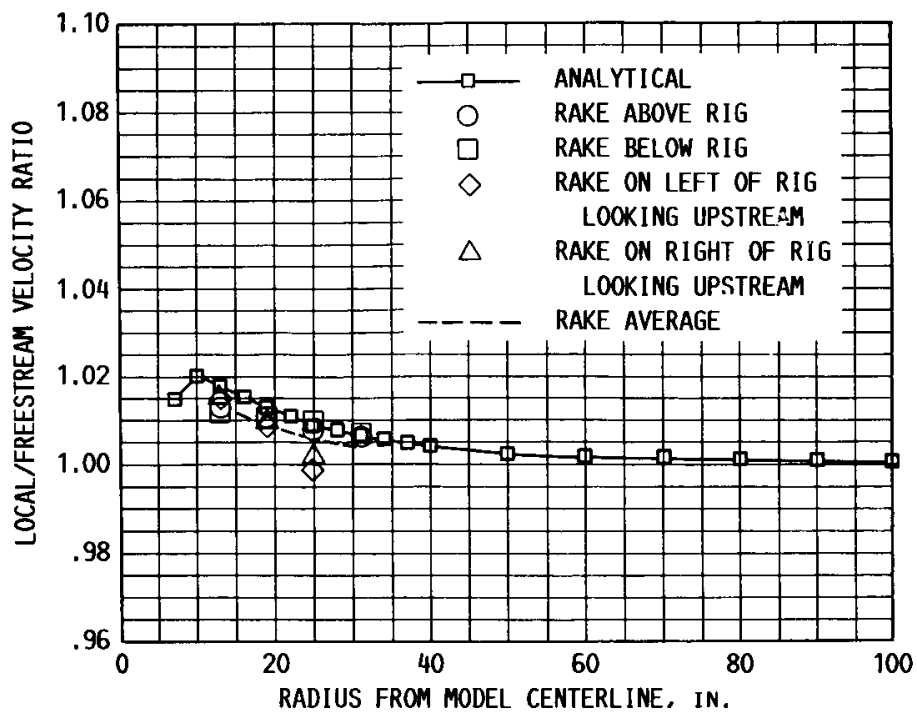

FIGURE 4. - COMPARISON OF ANALYTICAL AND EXPERIMENTAL VELOCITY RAIIOS AROUND THE COUNTERROTATING PROPELLER TEST RIG AT THE PROPELLER PLANE AT MACH 0.60.

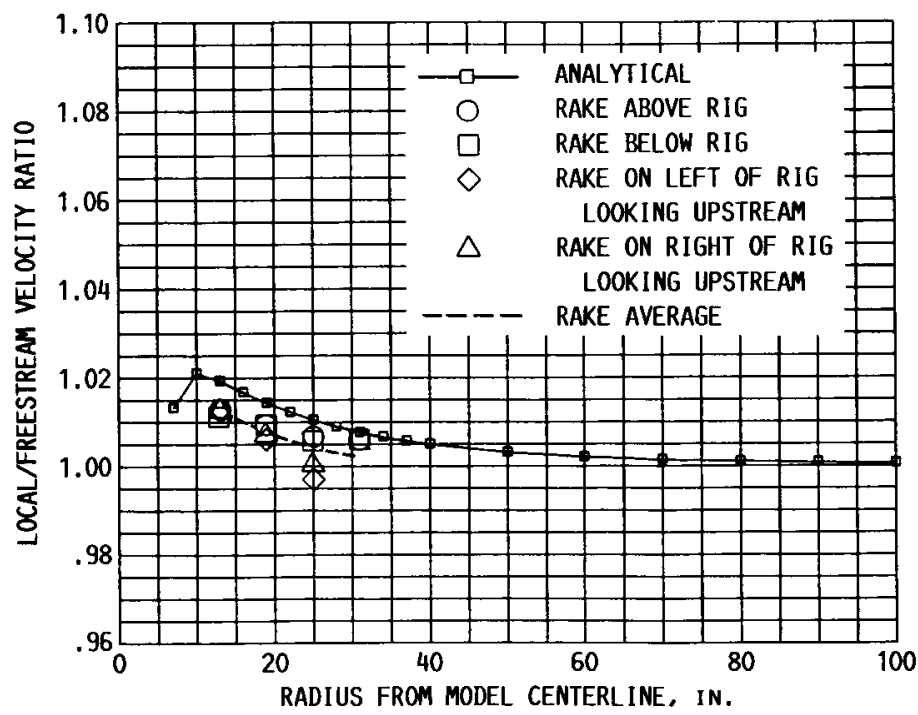

FIGURE 5. - COMPARISON OF ANALYTICAL AND EXPERIMENTAL VELOCITY RATIOS AROUND THE COUNTERROTATING PROPELLER TEST RIG AT THE PROPELLER PLANE AT MACH 0.70 . 


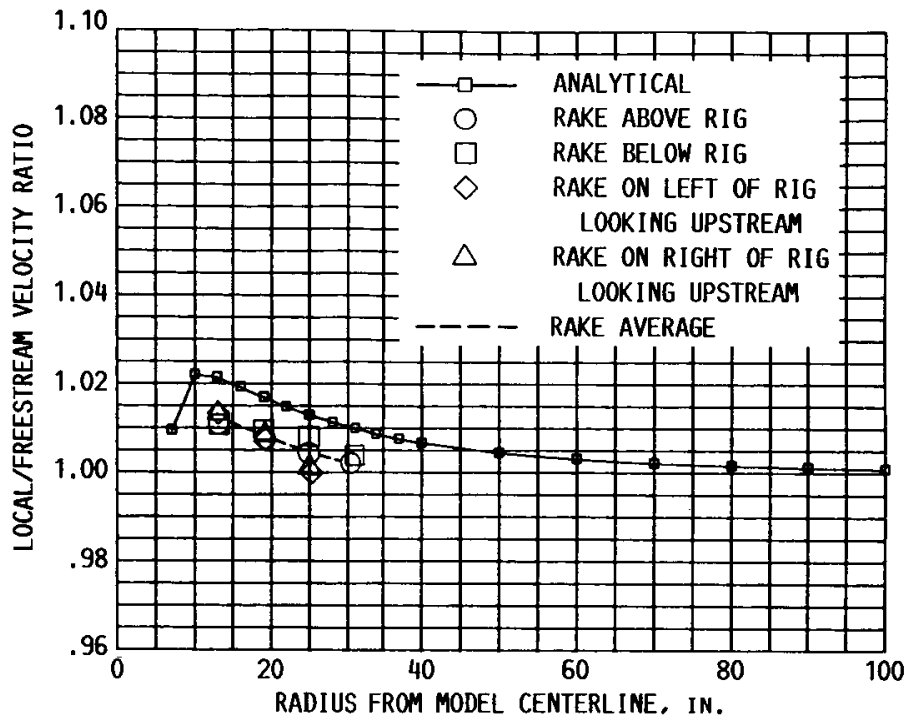

FIGURE 6. - COMPARISON OF ANALYTICAL AND EXPERIMENTAL VELOCITY RATIOS AROUND THE COUNTERROTATING PROPELLER TEST RIG AT THE PROPELLER PLANE AT MACH 0.80 .

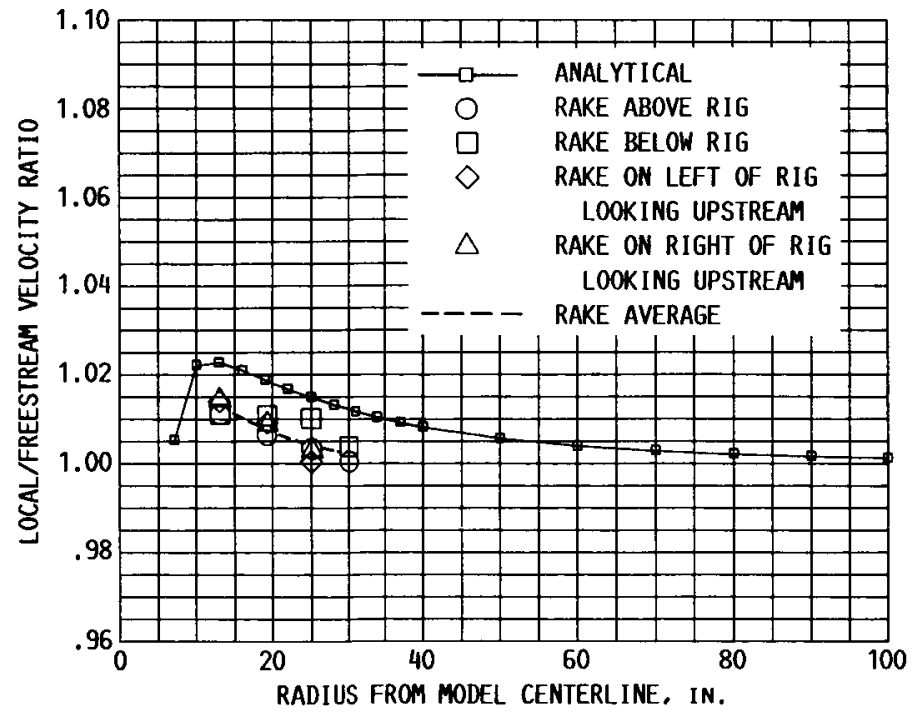

FIGURE 7. - COMPARISON OF ANALYTICAL AND EXPERIMENTAL VELOCITY RATIOS AROUND THE COUNTERROTATING PROPELLER TEST RIG AT THE PROPELLER PLANE AT MACH 0.85 . 


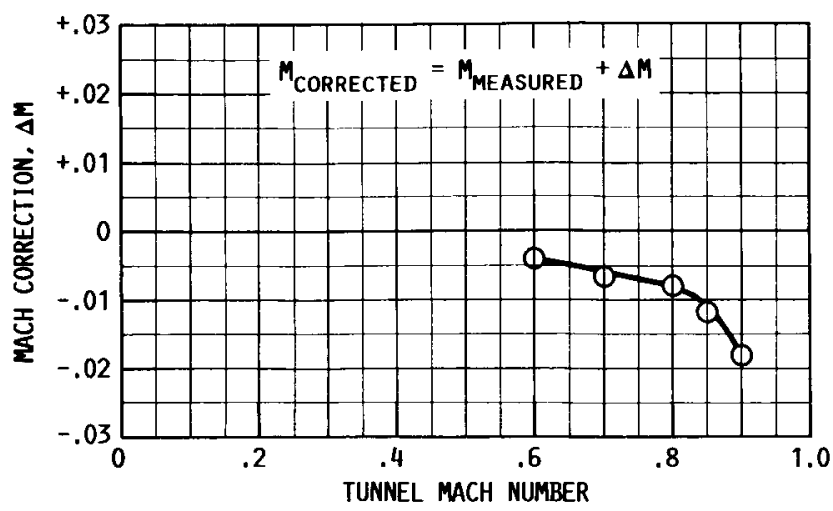

FIGURE 8. - MACH NUMBER INTERFERENCE CORRECTIONS FOR COUNTERROTATING PROPELLER TEST RIG IN POROUS WALL NASA LEWIS $8 \times 6$ FOOT WIND TUNNEL.

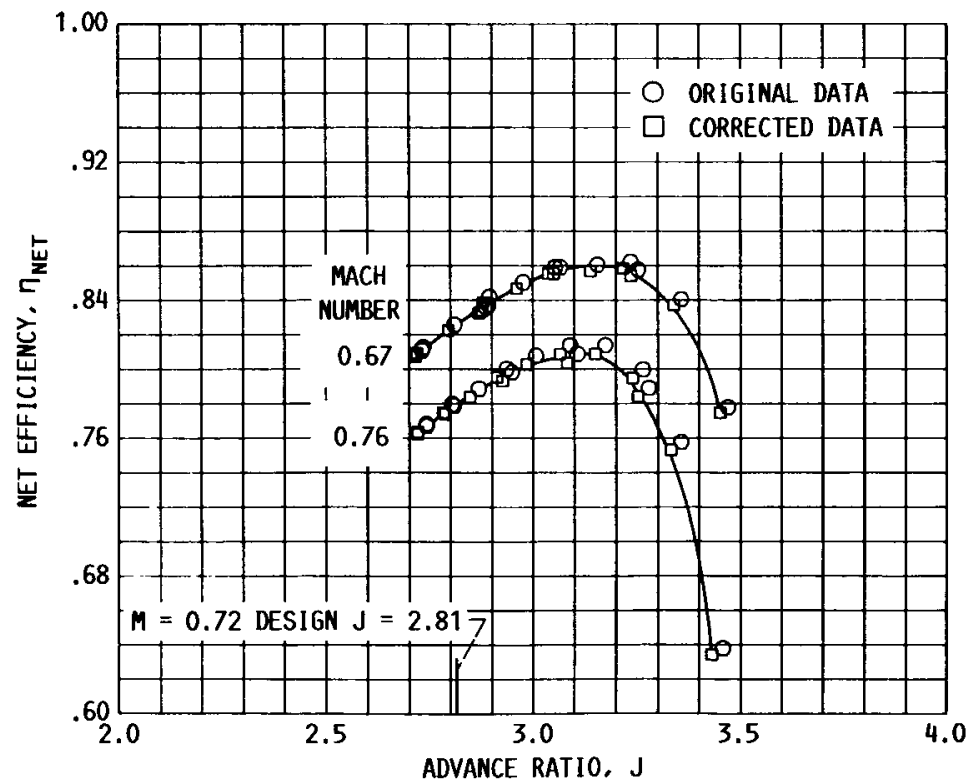

FIGURE 9. - EFFECT OF INTERFERENCE CORRECTIONS ON COUNTERROTATING PROPELLER NET EFFICIENCY DATA AT MACH 0.67 AND 0.76. (BLADES: F7/A7, ANGLES: 58.5/55.7.) 


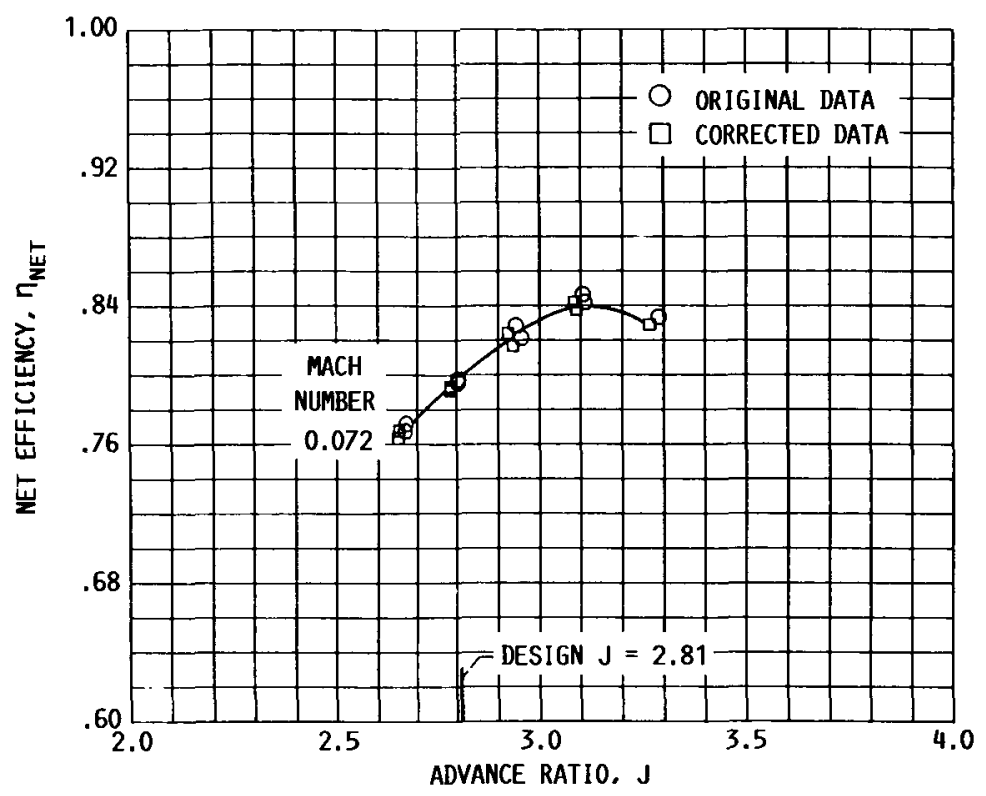

FIGURE 10. - EFFECT OF INTERFERENCE CORRECTIONS ON COUNTERROTATING PROPELLER NET EFFICIENCY DATA AT MACH 0.72.

(BLADES: F7/A7. ANGLES: 58.5/55.7.)

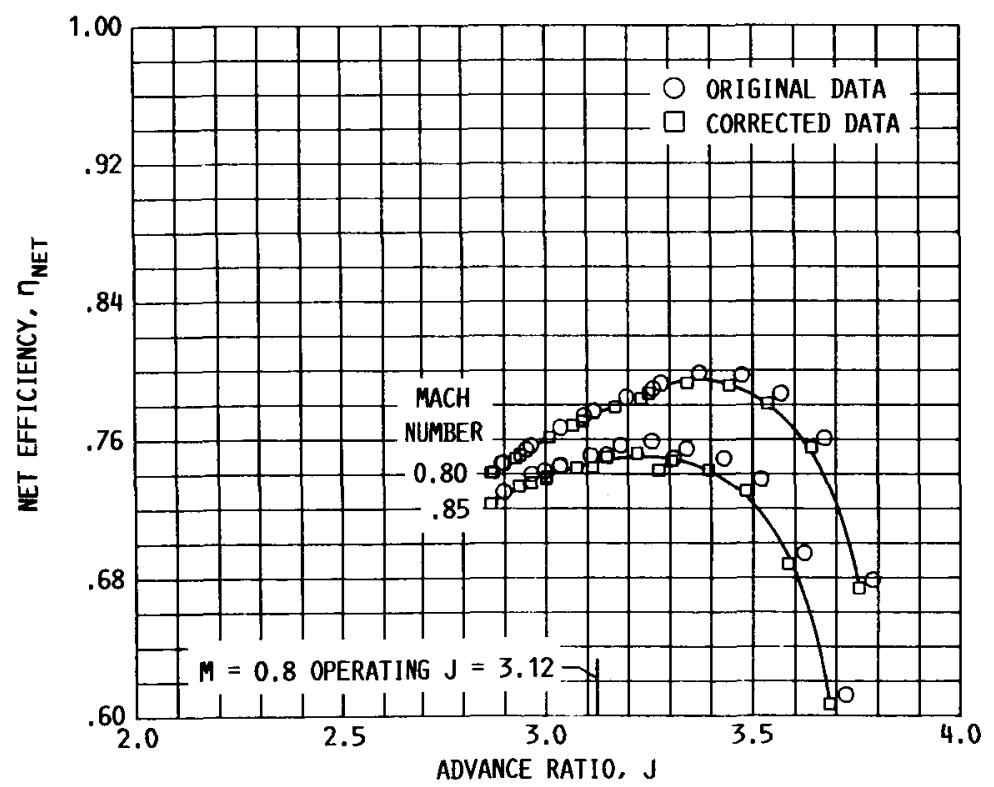

FIGURE 11. - EFFECT OF INTERFERENCE CORRECTIONS ON COUNTERROTATING PROPELLER NET EFFICIENCY DATA AT MACH 0.80 AND 0.85. (BLADES: F7/A7. ANGLES: 61.2/57.9.) 


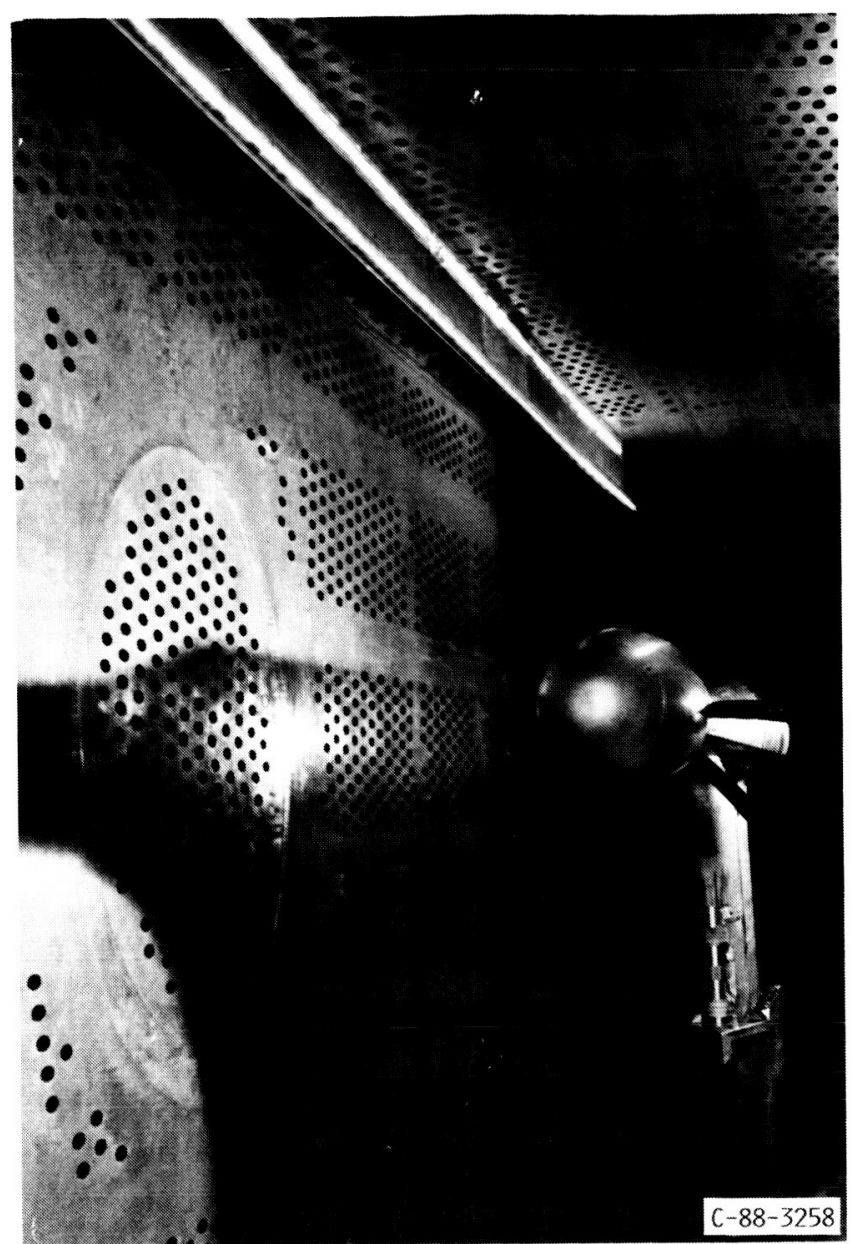

FIGURE 12. - COUNTERROTATING PROPELLER TEST RIG AND 20-FO0T STATIC TUBE IN NASA LEWIS $8 \times 6$ FOOT WIND TUNNEL FOR MEASURING WALL INTERFERENCE EFFECTS DUE TO THRUST.

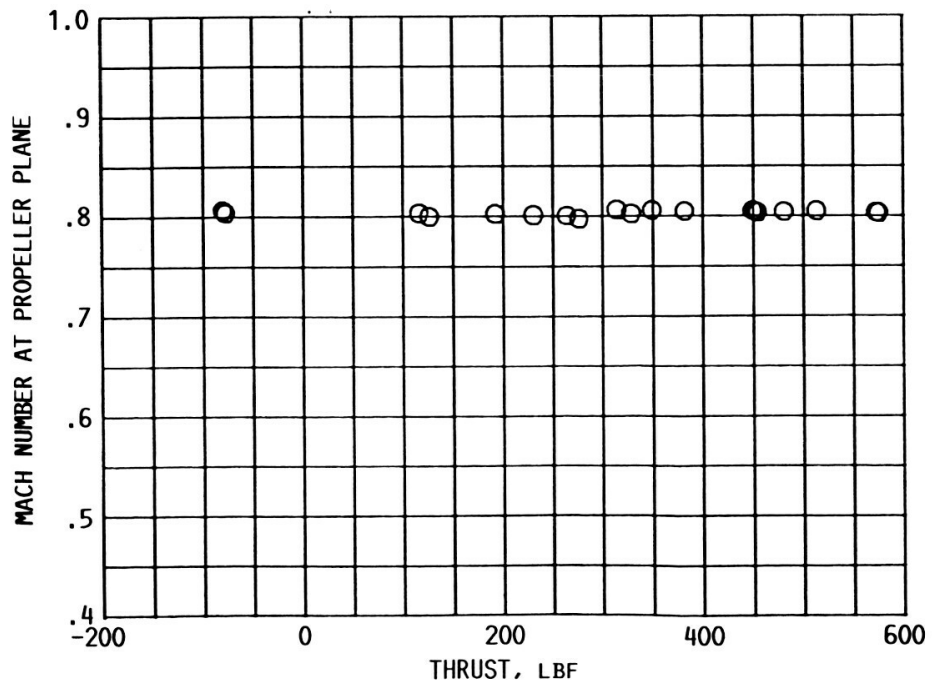

FIGURE 13. - EFFECT OF PROPELLER THRUST ON PROPELLER PLANE MACH NUMBERS NEAR THE FLOOR AT $M=0.80$.

ORIGINAL, PAGE IS
OE BOOR QUALITY 


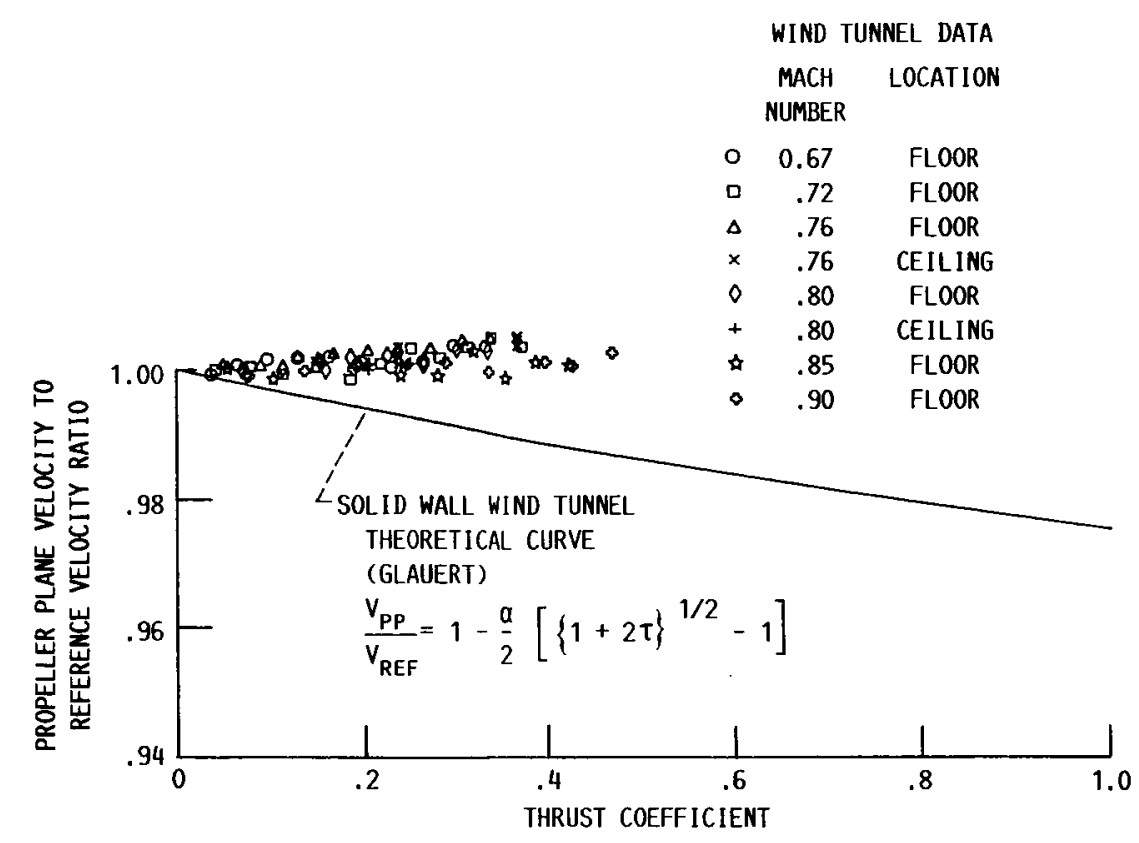

FIGURE 14. - COMPARISON OF THRUST EFFECT ON WIND TUNNEL VELOCITIES CALCULATED FROM THE SOLID WALL WIND TUNNEL INTERFERENCE EQUATION AND POROUS WALL $8 \times 6$ FOOT WIND TUNMEL DATA.

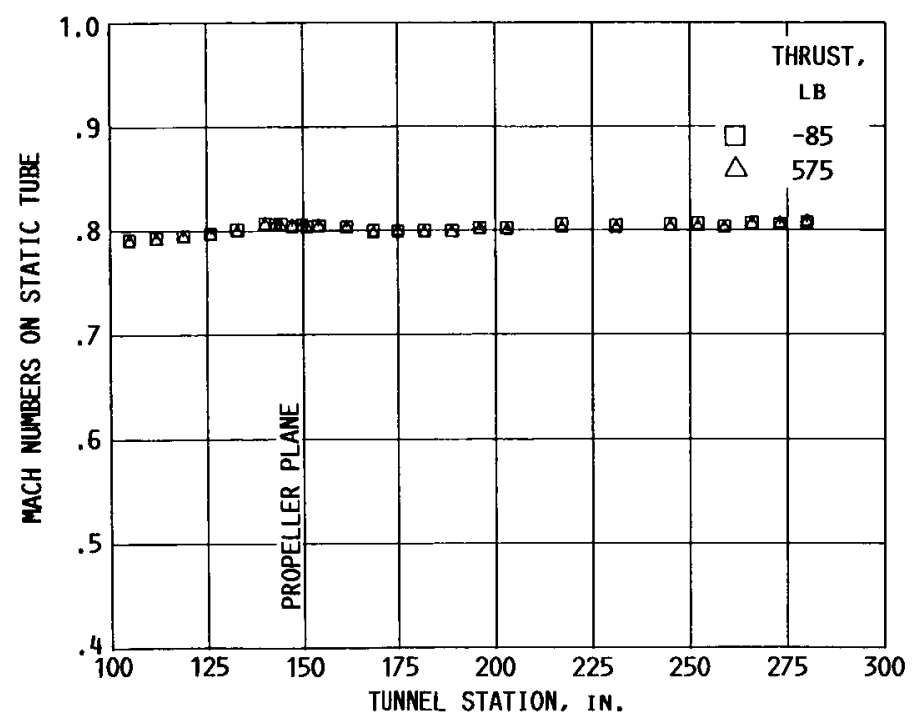

FIGURE 15. - EFFECT OF PROPELLER THRUST ON MACH NUMBERS OVER THE LENGTH OF THE TUNNEL TEST SECTION NEAR THE CEILING AT MACH 0.80 . 


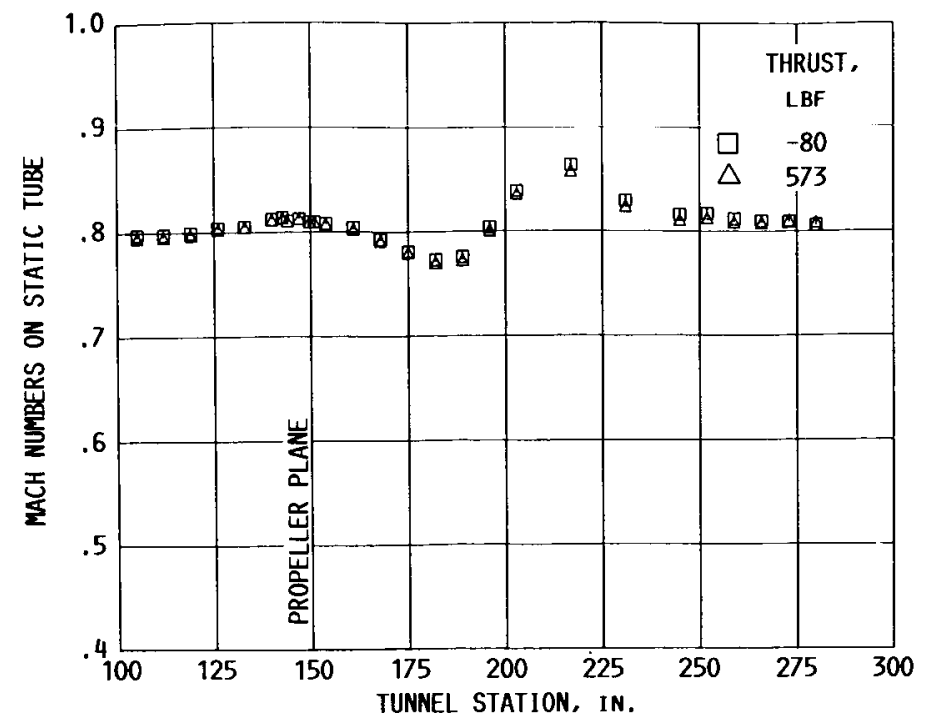

FIGURE 16. - EFFECT OF PROPELLER THRUST ON MACH NUMBERS OVER THE LENGTH OF THE TUNNEL TEST SECTION NEAR THE FLOOR AT MACH 0.80 .

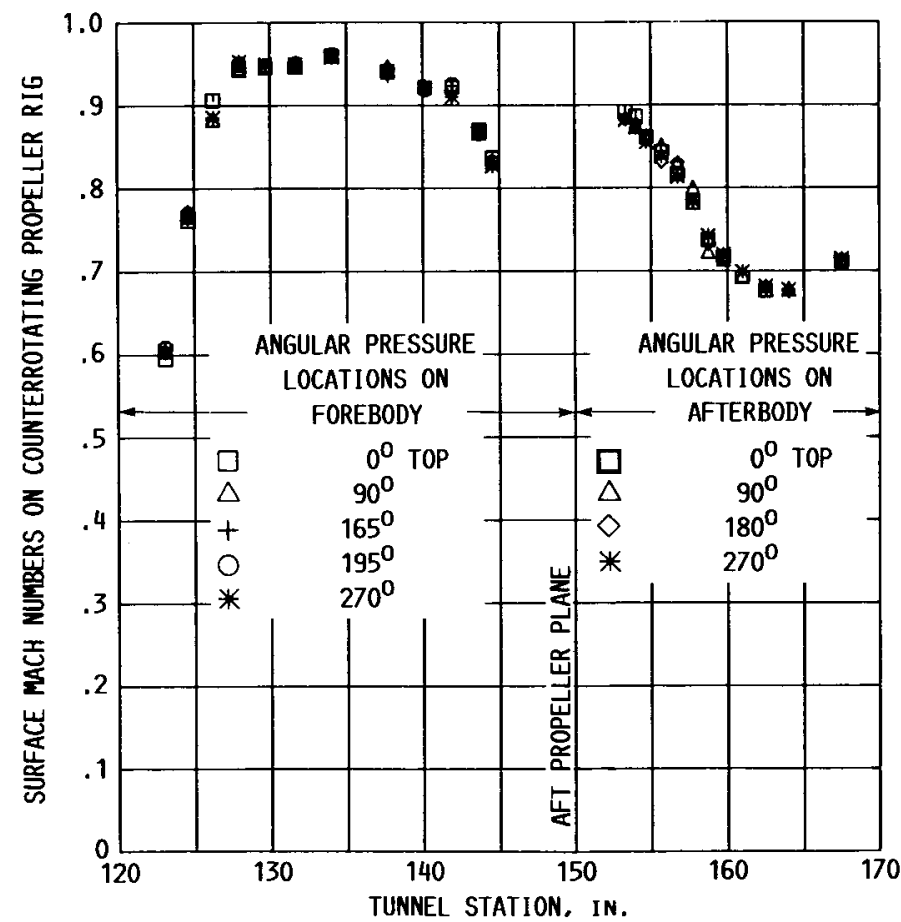

FIGURE 17. - MACH NUMBERS AT DIFFERENT ANGULAR POSITIONS ON THE SURFACE OF THE COUNTERROTATING PROPELLER TEST RIG AT MACH 0.80. WINDMILL CONDITIONS ( $T=-77$ LB, $P Q A=-0.098, J=3.96)$. 


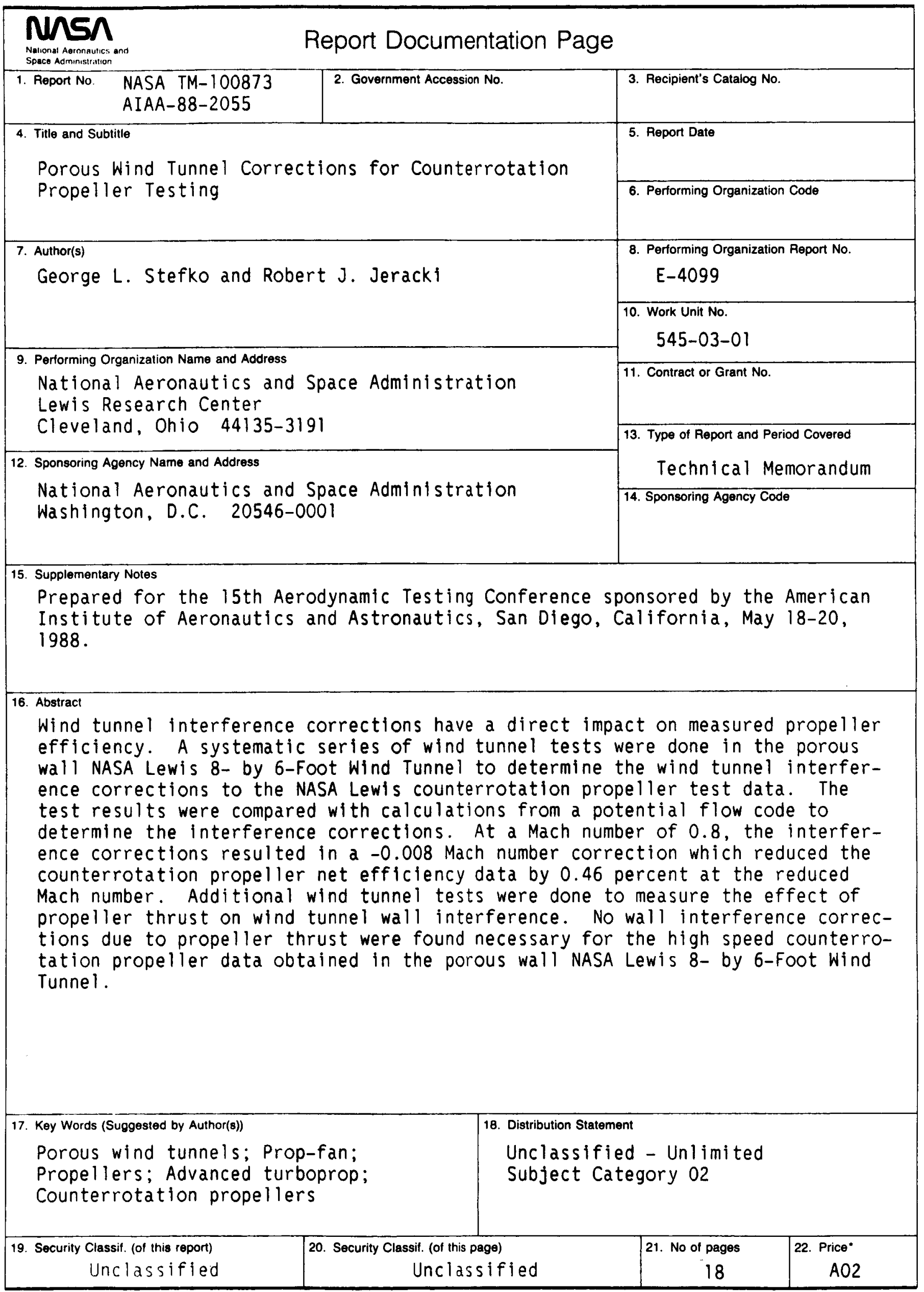

